\title{
Numerical modeling of circular, square and rectangular concrete columns wrapped with FRP under concentric and eccentric load
}

\section{Modelagem de pilares de concreto com seção circular, quadrada e retangular reforçados com PRF e solicitados por força centrada e excêntrica}
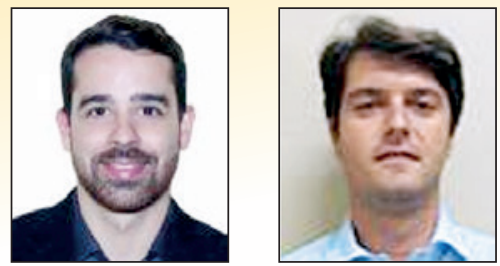

\author{
D. S. OLIVEIRA \\ diogooliveira@ufv.br \\ https://orcid.org/0000-0002-4771-8971 \\ R. CARRAZEDO \\ carrazedo@sc.usp.br \\ https://orcid.org/0000-0002-9830-7777
}

\begin{abstract}
In this paper, the finite element method was used for the numerical modeling of columns with square, rectangular and circular cross sections wrapped with FRP. The numerical modeling was successfully calibrated with the experimental data considering axial load, axial strain and transverse strain. The distribution of compressive stresses in the cross section of the column indicates that for centered load, circular cross sections have uniform distribution and for square and rectangular sections the effective confined concrete was defined by parabolas and concentrates next to the rounded corners. For eccentric load, the effective confined region moves to the most confined edge, thus, this does not reduce the gain for square and rectangular columns, but is unfavorable for circular columns.
\end{abstract}

Keywords: strengthening of columns, fiber reinforced polymers, concrete confinement.

\section{Resumo}

Neste artigo é apresentada a modelagem numérica em elementos finitos de pilares com seções transversais circular, quadrada e retangular solicitados por força centrada e excêntrica, reforçados com PRF. O modelo numérico foi calibrado com os resultados experimentais e indicou boa compatibilidade de forças axiais, deformações axiais e deformações transversais. Foi demonstrada a distribuição das tensões de compressão na seção transversal do pilar, indicando que no caso de solicitação por força centrada as seções transversais circulares apresentam distribuição uniforme e os pilares com seção quadrada e retangular a região de concreto confinado fica limitada por parábolas e se concentram junto aos cantos arredondados. Para o caso de força excêntrica, a região efetivamente confinada se desloca junto à borda mais comprimida, sendo que isso não reduz o ganho de resistência para seções quadradas e retangulares, mas reduz a eficiência do reforço em seções circulares.

Palavras-chave: reforço de pilares, polímeros reforçados com fibras, confinamento do concreto. 


\section{Introduction}

Fiber Reinforced Polymers (FRP) are materials composed of fibers combined with a polymeric matrix. They appear as an alternative in relation to conventional materials for strengthening and rehabilitation of structures. FRP is lightweight, non-corrosive and has high tensile strength. In fabric format, the FRP can be used to wrap the structure to promote strengthening. Fibers and resins are expensive if compared to traditional materials; however, they allow strengthening of the structure in a relatively short time and demand a lower degree of structure intervention. In addition to this, it is possible to apply them in places with difficult access (ACl 440.2R-08 [1]).

FRP is used in concrete columns in the shape of a jacket to obtain strength improvement through the lateral confinement mechanism. Richart et al. [2] affirm that this mechanism is more efficient for circular columns cross section because the lateral confinement pressure is uniformly transferred to the concrete by the membrane effect. Complementing the concept, Lam e Teng [3] indicate that, for columns with different cross sections than circular, the distribution of lateral confinement pressures is not uniform, reducing the confinement effect on concrete. For square and rectangular shapes, the cross section is not completely confined, because the lateral pressure is developed only near the rounded corners, where the membrane effect is also developed (Shehata [4]). Because the FRP laminate does not have bending strength, the membrane effect is not developed in the flat sides of the cross section. Consequently confining of concrete does not occur in this region. For rectangular cross sections, the bigger the aspect ratio (ratio between the major and minor side) the lower is the effectiveness of concrete confinement. In addition, the efficiency of FRP confinement is also influenced by the load eccentricity, creating a coupled effect that is related to the confinement level, the cross sectional shape, and the load eccentricity (Maaddawy [5]).

\subsection{Objective}

This research aims to demonstrate, through numerical modeling using the finite element method, the distribution of the compressive axial stresses in columns with different cross sections confined by FRP. In addition, columns with concentric and eccentric load were considered in order to identify the relationship of these stress distributions with the strength efficiency.

\subsection{Columns strengthened with FRP mobilizing confinement effects}

In the last decades, several researches have indicated the main factors that influence the structural behavior of columns strengthened with FRP based on the confinement mechanism. Among them, the shape of the columns cross section, the radius of the rounded corners and the load eccentricity are one of the most important parameters and that are related to the columns geometry.

In relation to the radius of the rounded corners, the larger is the ratio between the radius to the cross sectional side, the greater is the confinement efficiency (Nisticò [6]) and, fixing the columns cross section dimensions and the number of FRP layers, the increase in

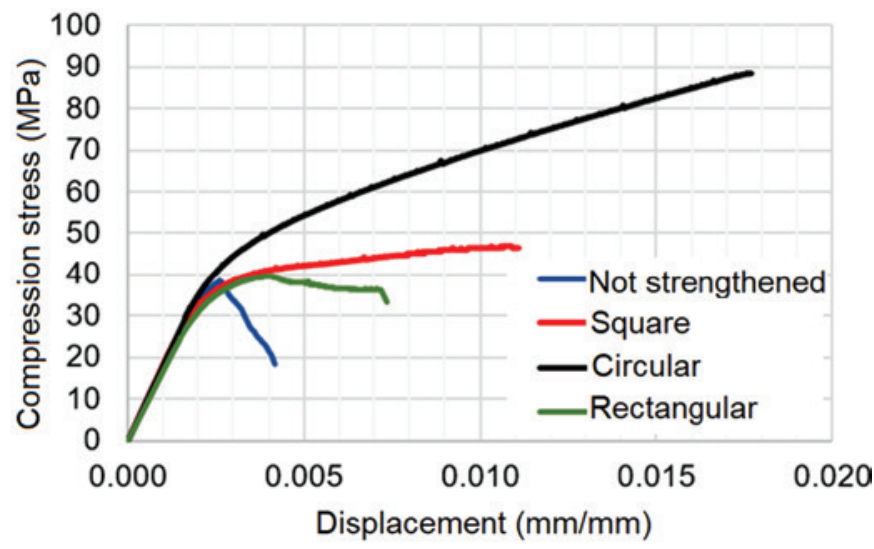

Figure 1

Confinement efficiency of FRP for different cross section shape tested by Carrazedo [17]

radius improves the strain capacity FRP (Rochette e Labossière [7] e Yang [8]).

Shehata [4], Carrazedo [9], Youssef et al.[10]a stress-strain model for concrete confined by fiber reinforced polymer (FRP, Ilki et al. [11]68 reinforced concrete columns were tested under uniaxial compression after being jacketed externally with carbon fiber-reinforced polymer (CFRP, Toutanji et al. [12], Maalej et al. [13], Micelli and Modarelli [14] and Tan et al. [15] found that circular columns cross sections have greater effectiveness of confinement, followed by the square cross section and finally the rectangular ones with the lowest efficiency. In the circular sections, the membrane effect forms along the entire section perimeter, allowing a uniform distribution of lateral confining pressure. For different sections than the circular one, the small bending strength of the FRP jacket does not allow that large pressures be applied in flat sides. Since a membrane has a very low bending stiffness a jacket curvature in necessary to restrict the transversal loads in the median plane. Machado [16] and Carrazedo [17] comment that circular and square sections have a stress strain curve with a second ascending branch, whereas for rectangular sections this becomes descending, as shown in Figure 1.

Experimental tests in rectangular cross sections performed by Chaallal [18], Harajli [19], Ilki et al. [11]68 reinforced concrete columns were tested under uniaxial compression after being jacketed externally with carbon fiber-reinforced polymer (CFRP, Kumutha et al. [20], Wu and Wei [21], Yan and Pantelides [22], Ozbakkaloglu [23] and Tan et al. [15] showed that the greater the aspect ratio, smaller is the axial strength promoted by the FRP jacket. Because of the large straight sides of the section, even if a high lateral deformation occurs, the jacket is not capable of mobilizing considerable passive confinement. Wu and Wei [21] have stated that for aspect rations greater than two, the strengthening increase is insignificant. However, it is common to have columns with high aspect ratio in reinforced concrete buildings.

For rectangular cross sections, Fib [24] considers that the effective confined region is delimited by parabolas beginning at $45^{\circ}$, as indicated in Figure 2a. Following this concept, Tan et al. [15] indicate that these parabolas touch each other when the aspect ratio is above a critic value of $\alpha_{c r}=h / b$, which starts from 2 , for 
$r=0$, until 3, for $r=b / 2$. Above these limits, the parabolas cross each other, (see Figure 2b). In opposition to this concept, $\mathrm{ACl}$ $440.2 \mathrm{R}-08$ [1] indicates that the parabolas begin with inclination parallel to the cross section diagonal (see Figure 2c). Thus, regardless of the aspect ratio, the parabolas would never touch, as suggested by Harajli [19] on Figure 2d. Considering this disparity of concepts, it is understood that numerical modeling can clearly demonstrate the configuration of the effectively confined region. Carrazedo [9] observed in columns with circular cross sections that the gain provided by the confinement is smaller in the presence of load eccentricity in comparison to the situation of concentric load. For square and rectangular sections the eccentricity was not as detrimental as in circular sections. In some cases the gain in an eccentric situation was higher than in the concentric force situation.

Maaddawy [5] observed in their tests that increases in strength and ductility were greatly affected by the variation of the cross section geometry under concentric load and that the respective gains were smaller under small eccentricities. He pointed the need for further studies in the area that to better observe the relationship between eccentricity and cross sectional shape. To highlight these parameters, he indicates that these studies should consider large values of eccentricities and or lower level confining pressure.

The analytical model available in standard recommendations for the design of square and rectangular columns under eccentric load is the only one proposed by Rocca et al. [25] and indicated in ACl 440.2R08 [1]. However, this model does not consider a different configuration for the effective confined concrete region in sections of square and rectangular columns when in eccentric load. It adopts the same stress distribution considered for the concentric load situation. In addition, there are no theoretical models in standard recommendations to design circular columns under eccentric load strengthening

These confirmations point out the necessity for further investigation regarding the distribution of compressive stress which is effectively confined by FRP, and one of the best ways to do this is by using numerical modeling.

\section{Constitutive model for concrete under passive confinement}

\subsection{Plasticity model for concrete}

Most studies on FRP strengthening system have been experimental tests. This is justified due to the difficulty to represent the passive confinement of concrete numerically, which has as a basic principle the transverse dilation in the plastic zone of stress strain curve. More recently a constitutive model called Concrete Damaged Plasticity (CDP) was incorporated in the software ABAQUS [26]. This model uses the plastification function proposed by Lubliner [27] and the modifications proposed by Lee and Fenves [28]. In the present work, the damage resources of this model were not used, only the plasticity criterion was used to represent the behavior of the concrete. The main parameters that define the model are: yielding surface, plastic potential and the hardening law. In addition to these data it was necessary to define the compressive stress strain curve of concrete and the behavior under tensile stresses.

\subsection{Yielding surface}

The function of the yielding surface of CDP is defined by the following equation:

$F\left(\bar{\sigma}, \tilde{\varepsilon}^{p l}\right)=\frac{1}{1-\alpha}\left(q-3 \alpha p+\beta\left(\tilde{\varepsilon}^{p l}\right)\left(\widehat{\sigma}_{m a ́ x}\right)-\gamma\left(-\widehat{\sigma}_{m a ́ x}\right)-\bar{\sigma}_{c}\left(\tilde{\varepsilon}^{p l}\right)\right)$

where:

$p-$ is the effective hydrostatic pressure;

$q-$ is the equivalent Mises stress;

$\bar{\sigma}-$ is the tensile tensor of effective stress;

$\widehat{\sigma}_{\text {máx }}-$ is the eigenvalues vector of tensor $\bar{\sigma}$;

$\tilde{\varepsilon}^{p l}-$ is the vector of equivalent plastic deformations.

The function $\beta\left(\tilde{\varepsilon}^{p l}\right)$ can be computed by:

$\beta\left(\tilde{\varepsilon}^{p l}\right)=\frac{\bar{\sigma}_{c}\left(\tilde{\varepsilon}_{c}^{p l}\right)}{\bar{\sigma}_{t}\left(\tilde{\varepsilon}_{t}^{p l}\right)}(1-\alpha)-(1+\alpha)$

which $\bar{\sigma}_{c}$ and $\bar{\sigma}_{t}$ are the effective compression and tensile stress and, $\tilde{\varepsilon}_{c}^{p l}$ and $\tilde{\varepsilon}_{t}^{p l}$ are the vectors of plastic deformations when in compression and tensile, respectively.

The variable $\alpha$ is defined from the initial compression stress in biaxial and uniaxial state $\left(\sigma_{b 0}\right.$ and $\sigma_{c 0}$, respectively), which can be resumed by the following equation:

$\alpha=\frac{\sigma_{b 0}-\sigma_{c 0}}{2 \sigma_{b 0}-\sigma_{c 0}}$

According to Lubliner et al. [27], for concrete, the ratio $\sigma_{\mathrm{b} 0} / \sigma_{\mathrm{c} 0}$ varies from 1 to 1.16 . The $\gamma$ coefficient is defined by the

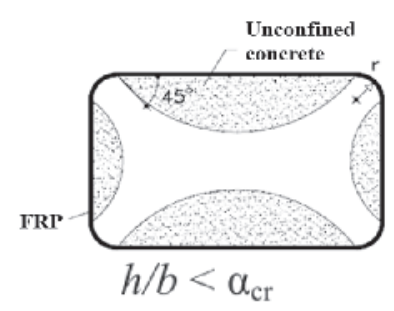

(a)

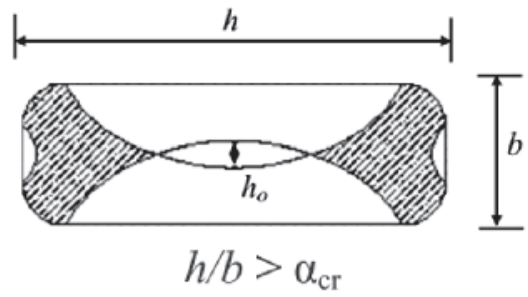

(b)

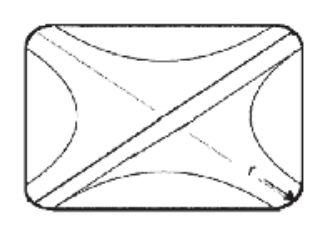

(c)

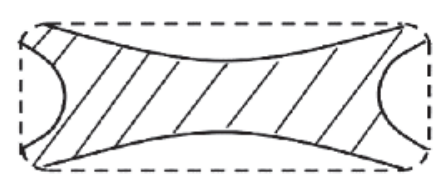

(d)

Figure 2

Different configurations for regions of effective confined concrete: (a) Fib [24]; (b) Tan et al. [15]; (c) ACl 440.2R-08 [1] and (d) Harajli [19] 
comparison between compression and tensile meridian, respectively, which results in the following equation:

$\gamma=\frac{3\left(1-K_{c}\right)}{2 K_{c}-1}$

which $\mathrm{K}_{\mathrm{c}}$ is defined by the relation between the Mises stress in tensile meridian and stress Mises in compression meridian, that is: $K_{c}=\frac{q_{M T}}{q_{M C}}$

This coefficient can vary from 0.5 until 1 , but for the concrete generally it is assumed as $2 / 3$ (Lubliner et al. [27]). In Figure 3 the cross section for the yielding surface in the Nadai plane is shown.

\subsection{Plastic potential}

The plastic potential uses the Drucker-Praguer hyperbolic function and assumes a non-associative flow, as follows:

$G=\sqrt{\left(\epsilon \sigma_{t 0} \tan \psi\right)^{2}+q^{2}}-p \tan \psi$

which:

$\sigma_{\mathrm{t} 0}-$ is the tensile stress in the uniaxial state;

$\in-$ is the eccentricity that defines the rate at which the hyperbolic function approaches to an asymptotic line, that is, the shape of the plastic potential curve in the meridians tends to be a straight line when the eccentricity tends to zero. For concrete the usual value is adopted equal to 0.1 ;

$\psi-$ is the dilation angle measured in the meridian plane for large values of confining stress. For concrete, the typical values vary from $36^{\circ}$ until $56^{\circ}$ (Lubliner et al. [27]).

In CDP the concrete capacity of transversal expansion, when in compression strain, is governed by the dilation angle $\psi$. This behavior is essential to represent the passive confinement of concrete. If the lateral confining pressure and the stress strain curve of the unconfined concrete were fixed, the larger the angle of expansion, the greater are the concrete hardening and the lateral strain. In summary, in order to obtain a level of concrete hardening the solution involves the definition of the dilation angle and the concrete stress strain curve. For concrete confinement in columns the calibration can be performed considering the tensile strain of the FRP as parameter.

Ozbakkaloglu et al. [29] observed that the bigger the lateral confining pressure the smaller is the dilation angle. In addition, the dilation angle tends to decrease with the plastic strains increase. They proposed a numerical model that considers this variation of dilation angle. However, this model is considered only for circular cross section specimens confined with FRP and subjected to uniform lateral pressure. For columns with a rectangular section, where the confinement is not uniform, each region is subjected to a different confining pressure and plastic strain. Then, it is still necessary to improve this model to be used in rectangular columns. Despite the study by Ozbakkaloglu et al. [29], it is understood that satisfactory results can be obtained by using a fixed value for the dilation angle as adopted by the CDP obtained by calibration with the experimental values as will be shown in the following items.

\subsection{Hardening law}

The CDP hardening law is defined by the following plastic strain vector: $\tilde{\varepsilon}^{p l}=\left[\begin{array}{l}\tilde{\varepsilon}_{t}^{p l} \\ \tilde{\varepsilon}_{c}^{p l}\end{array}\right] \hat{h}\left(\widehat{\sigma}_{m a ́ x}, \tilde{\varepsilon}^{p l}\right) \cdot \hat{\varepsilon}^{p l}$ which:

$\tilde{\varepsilon}_{t}^{p l}-$ is the vector that represents de equivalent tensile plastic strain;

$\tilde{\varepsilon}_{c}^{p l}$ - is the vector that represents de equivalent compression plastic strain;

$\widehat{h}$ - is the vector that defines the direction of hardening vector;

$\hat{\varepsilon}^{p l}-$ is the eigenvalues of plastic strains tensor.

For model data input it is necessary the concrete plastic stress strain curve in uniaxial compression state. For tensile behavior it is possible to provide only the tensile strength and tensile fracture energy.

\subsection{Stress strain curve}

In order to define the stress strain curve in compression Wee et al. [30] equation was used (see Equation 8). This curve can represent the entire post peak branch.

$\sigma_{c}=\left[\frac{k_{1} \beta_{0}\left(\frac{\varepsilon}{\varepsilon_{c}}\right)}{k_{1} \beta_{0}-1+\left(\frac{\varepsilon}{\varepsilon_{c}}\right)^{k_{2} \beta_{0}}}\right]$

Which:

$k_{1}=\left(\frac{50}{f_{c}}\right)^{3} \quad$ and $\quad k_{1}=\left(\frac{50}{f_{c}}\right)^{1.3}$

$\varepsilon_{c}=0.00078 f_{c}^{(1 / 4)}$

$\beta_{0}=\frac{1}{1-\frac{f_{c}}{\varepsilon_{c} E_{c}}}$

$\mathrm{E}_{\mathrm{c}}$ - is the concrete Young modulus;

$\varepsilon-$ is the concrete strain;

$\varepsilon_{\mathrm{c}}-$ is the strain concrete peak strength;

$\mathrm{f}_{\mathrm{c}}$ - is the unconfined concrete strength.

For concrete lower than $50 \mathrm{MPa}$, the variables assumes the values $\mathrm{k}_{1}=1$ and $\mathrm{k}_{2}=1$.

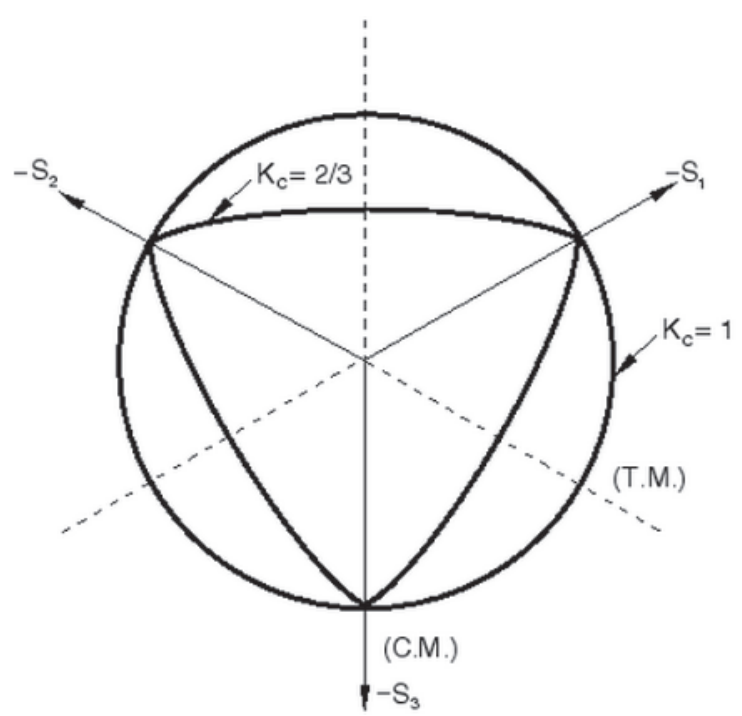

Figure 3

Cross section of yielding surface at Nadai plane, in which -S1,-S2 and -S3 are the compression stress at the three principal directions (ABAQUS [26]) 
Table 1

Values for $G_{f 0}$ (CEB-FIB [31])

\begin{tabular}{cc}
\hline $\begin{array}{c}\text { Coarse aggregate diameter } \\
(\mathbf{m m})\end{array}$ & $\begin{array}{c}\mathbf{G}_{\mathrm{fo}} \\
\text { (MPa.mm) }\end{array}$ \\
\hline 8 & 0.025 \\
16 & 0.030 \\
32 & 0.058 \\
\hline
\end{tabular}

\subsection{Tensile behavior for concrete}

For tensile fracture energy CEB-FIB [31] the following equation was used:

$G_{f}=G_{f 0}\left(\frac{f_{c m}}{f_{c m 0}}\right)^{0.7}$

which:

$\mathrm{G}_{\mathrm{f} 0}$ - is the tensile fracture energy related to the coarse aggregate size (see Table 1);

$\mathrm{f}_{\mathrm{cm}}$ - is the average compression strength of concrete;

$\mathrm{f}_{\mathrm{cm} 0}-$ is equal to $10 \mathrm{MPa}$.

\section{Table 2}

Column series tested by Carrazedo [17]

\begin{tabular}{|c|c|c|c|c|}
\hline \multirow{2}{*}{$\begin{array}{l}\text { Series } 1 \text { - Square cross section } \\
(150 \mathrm{~mm} \times 150 \mathrm{~mm}) \mathrm{r}=10 \mathrm{~mm}\end{array}$} & & \multicolumn{3}{|c|}{ Eccentricity (mm) } \\
\hline & & 0 & 10 & 20 \\
\hline & 0 & SOOr1 & S01r1 & SO2r1 \\
\hline \multirow[t]{2}{*}{ Number of FRP Layers } & 1 & S10r1 & S11r1 & S12r1 \\
\hline & 2 & S20r1 & S21r1 & $\mathrm{S} 22 \mathrm{r} 1$ \\
\hline Series 2 - Square cross section & & \multicolumn{3}{|c|}{ Eccentricity (mm) } \\
\hline \multirow[t]{2}{*}{$(150 \mathrm{~mm} \times 150 \mathrm{~mm}) \mathrm{r}=30 \mathrm{~mm}$} & & 0 & 10 & 20 \\
\hline & 0 & soOr3 & S01r3 & $\mathrm{s} 02 \mathrm{r} 3$ \\
\hline \multirow[t]{2}{*}{ Number of FRP Layers } & 1 & s10r3 & $\begin{array}{l}\text { S1 1r3-a } \\
\text { S1 1r3-b }\end{array}$ & - \\
\hline & 2 & s20r3 & S21r3 & $\mathrm{S} 22 \mathrm{r} 3$ \\
\hline Series 3 - Rectangular cross section & & \multicolumn{3}{|c|}{ Eccentricity $(\mathrm{mm})$} \\
\hline \multirow[t]{2}{*}{$(150 \mathrm{~mm} \times 225 \mathrm{~mm}) \mathrm{r}=30 \mathrm{~mm}$} & & \multicolumn{2}{|r|}{$\stackrel{y \leftrightarrow x}{\longrightarrow}$} & \\
\hline & & 0 & $x=30$ & $y=20$ \\
\hline \multirow[t]{2}{*}{ Number of FRP Layers } & 0 & $\mathrm{ROO}$ & $\mathrm{RO} 33$ & ROy2 \\
\hline & 2 & R20 & $\mathrm{R} 2 \times 3$ & $\mathrm{R} 2 \mathrm{y} 2$ \\
\hline Series 4 - Circular cross section & & \multicolumn{3}{|c|}{ Eccentricity $(\mathrm{mm})$} \\
\hline$(\mathrm{D}=150 \mathrm{~mm})$ & & 0 & & 20 \\
\hline \multirow{3}{*}{ Number of FRP Layers } & 0 & $\mathrm{COO}$ & & $\mathrm{CO} 2$ \\
\hline & 1 & C10 & & $\mathrm{C} 12$ \\
\hline & 2 & $\mathrm{C} 20$ & & $\mathrm{C} 22$ \\
\hline Series 5 - Square cross section & & \multicolumn{3}{|c|}{ Eccentricity (mm) / Radius (mm) } \\
\hline$(150 \mathrm{~mm} \times 150 \mathrm{~mm}) \mathrm{r}=10$ or $30 \mathrm{~mm}$ & $0 / 10$ & $0 / 30$ & $20 / 30$ & $20 / 30$ \\
\hline Number of FRP Lavers & 0 & X00 & X02 & - \\
\hline Number of FlP Layers & 1 & X10r1 & $\mathrm{X} 12 \mathrm{r} 1$ & $\mathrm{X} 12 \mathrm{r} 3$ \\
\hline
\end{tabular}

Columns nomenclature:

First letter: cross section shape $(S=$ square, $R=$ rectangular, $C=$ circular $)$

First number: number of FRP layers:

Second number: initial eccentricity $(\mathrm{cm})$. For rectangular the eccentricity is preceded by the direction $\mathrm{x}$ or $y$

Third number: (after letter $\mathrm{r}$ ): radius of the rounded corners $(\mathrm{cm})$.

\subsection{FRP behavior}

A linear elastic model type lamina in the software ABAQUS [26] thotropic materials in which the Young modulus and the Poisson's coefficient are defined for each three directions. Only values in the direction of the fibers were considered.

\subsection{Modeling of columns strengthened with FRP}

In order to perform the present study, columns from Carrazedo [17] were used. He tested 36 different short columns with circular, rectangular and square cross sections. Other variables such as radius of the rounded corners, concrete strength, number of FRP layers and the load eccentricity were analyzed. Table 2 summarizes all the specimens tested by Carrazedo [17].

\subsection{Finite elements mesh}

For concrete columns three-dimensional solid finite element C3D20R were used. This element is available in ABAQUS [26] and it has quadratic interpolation for the displacements with twenty nodes, three degrees of freedom per node and reduced integration. was used to represent the FRP behavior. This model is used for or- 


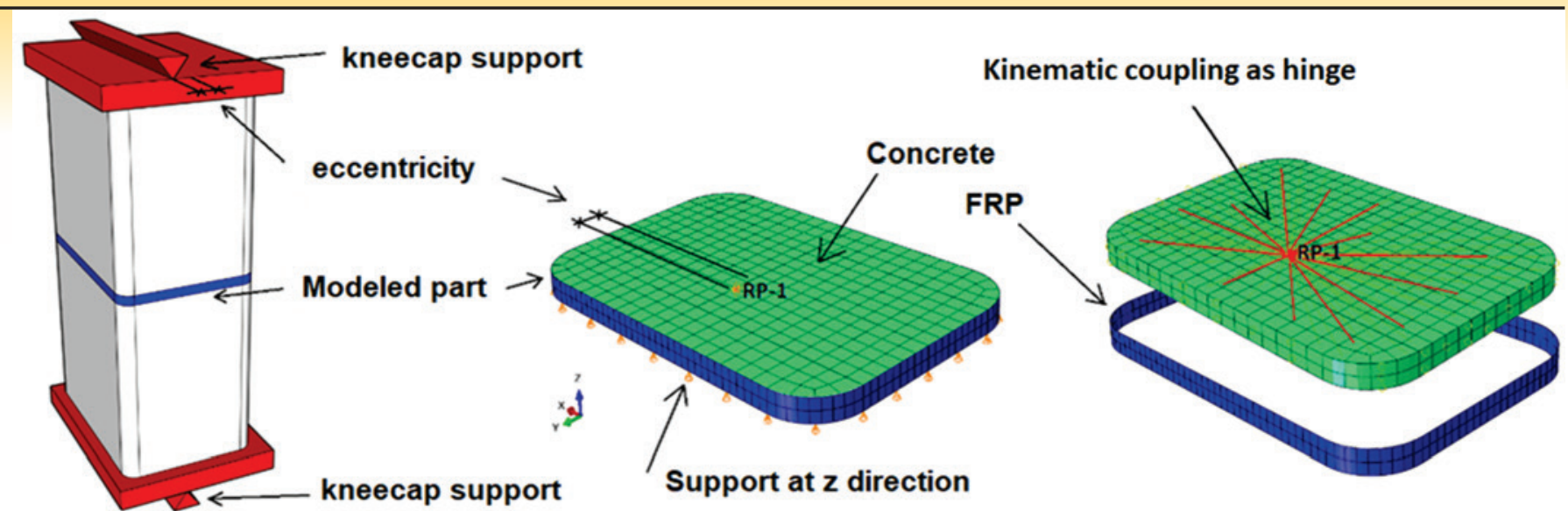

\section{EXPERIMENTAL TEST ESCHEME}

\section{Figure 4}

Typical finite element mesh of modeled columns

For FRP the three-dimensional S8R shell element with eight nodes, six degrees of freedom per node and reduced integration was used. Total interaction between concrete and FRP was considered by the command "TIE".

The columns were $400 \mathrm{~mm}$ long, however, only a $10 \mathrm{~mm}$ slice of the column was modeled (see Figure 4). At the columns ends, the support system was represented by the kinematic coupling of the section with a reference point. This restriction allows the section to have relative rotation in relation to the reference point, but remaining plane. For concrete and FRP, the finite element mesh was generated using the automatic mapped mesh feature and the maximum dimension of $7 \mathrm{~mm}$ was considered for the elements.

The load was applied by displacement steps automatically determined by ABAQUS [26]. The minimum step of $1.10^{-5}$ and maximum of $2.10^{-2}$ until the final displacement of $0.2 \mathrm{~mm}$ was adopted. In order to obtain the total column displacement, the axial displacement obtained in the modeling was multiplied by 40 , which is the ratio between the length of the modeled column and the length of the real columns tested experimentally. The model Modified Newton Method was used and the standard values of ABAQUS [26] was kept as convergence criteria.

\subsection{Materials properties}

Table 3 summarizes concrete properties experimentally obtained by Carrazedo [17]. The other parameters used in the numerical modeling are also indicated in the same table. For $\epsilon$ and $\sigma_{b 0} / \sigma_{c 0}$ the standard values of ABAQUS [26] were considered because these values did not affect the behavior of the modeled columns. $G_{f}$ was computed by CEB-FIP [31], as demonstrated by Equation 13 .
Several analyses have demonstrated that dilation angle is the parameter that most influences the numerical model behavior, because it is related to the lateral expansion of the concrete. For the analyzed concrete, several values were tested taking the load displacement curves of columns and the FRP tensile strain as references. These strains are directly associated to the lateral expansion of the concrete. The values that provided the best calibration were equal to $47^{\circ}$ for the concrete of $f_{c}=36.1 \mathrm{MPa}$ and $56^{\circ}$ for the concrete of $f_{c}=26.1 \mathrm{MPa}$.

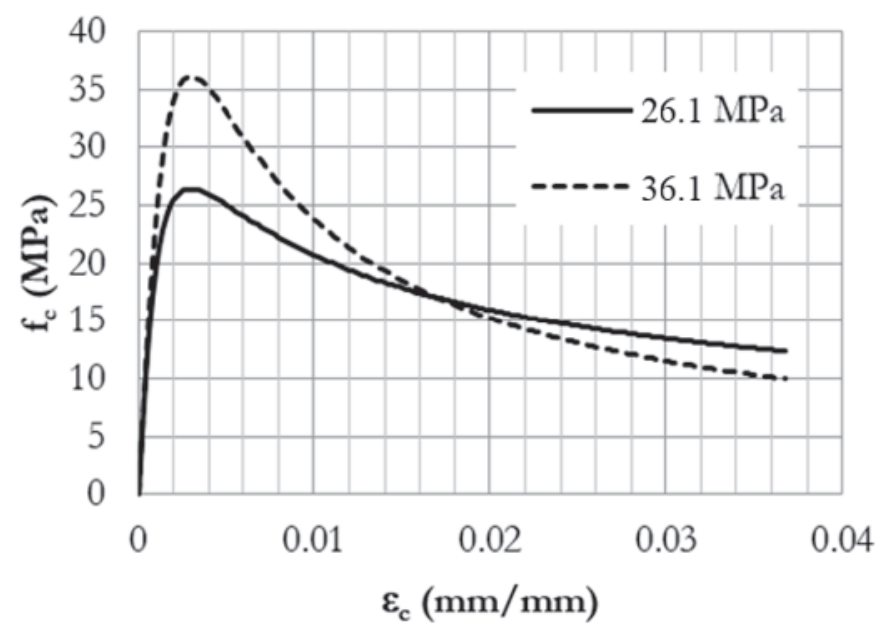

Figure 5

Stress strain curves for concrete of the modeled columns

Table 3

Concrete properties for modeling

\begin{tabular}{cccc}
\hline Parameter & Description & Series $\mathbf{1}$ to $\mathbf{4}$ & Series $\mathbf{5}$ \\
\hline$f_{\mathrm{c}}(\mathrm{MPa})$ & Unconfined strength (from experimental test) & 36.1 & 26.4 \\
$f_{f}(\mathrm{MPa})$ & Tensile strength & 3.33 & 2.92 \\
$\varepsilon_{\mathrm{c}}$ & Peak strain & 0.0030 & 0.0028 \\
$\mathrm{E}_{\mathrm{c}}(\mathrm{MPa})$ & Young modulus (from experimental test) & 28550 & 26000 \\
$\psi(\mathrm{Degree})$ & Dilation angle & $47^{\circ}$ & $56^{\circ}$ \\
$\epsilon$ & Eccentricity of flux potential & 0.1 & 0.1 \\
$\sigma_{\mathrm{b} o} / \sigma_{\mathrm{c} 0}$ & Ratio between compression biaxial/uniaxial & 1.16 & 1.16 \\
$\mathrm{G}_{\mathrm{f}}(\mathrm{N} / \mathrm{mm})$ & Tensile facture energy & 0.139 & 0.132 \\
\hline
\end{tabular}


Figure 5 shows the curves used for compressive stress strain curve for concrete obtained from the equation of Wee et al. [30]. For FRP modeling only the properties of the carbon fiber fabric were considered, the properties of the epoxy resin were not considered. The FRP behavior was considered linear elastic until the rupture, which was defined as the limit deformation of the fiber. Table 4 shows the properties of the fiber obtained in characterization tests performed by Carrazedo [17].

\section{Table 4}

Carbon fiber fabric properties for FRP modeling

\begin{tabular}{ccc}
\hline Parameter & Description & Value \\
\hline $\mathrm{f}_{\mathrm{f}}(\mathrm{MPa})$ & Tensile strength & 2757 \\
$\mathrm{E}_{\mathrm{f}}(\mathrm{MPa})$ & $\begin{array}{c}\text { Young modulus } \\
\text { Ultimate } \\
\text { rupture strain } \\
\varepsilon_{\mathrm{fu}}\end{array}$ & 218950 \\
$\mathrm{f}(\mathrm{mm})$ & $\begin{array}{c}\text { Equivalent fabric } \\
\text { thickness }\end{array}$ & $0.17 \times 10^{-3}$ \\
\hline
\end{tabular}
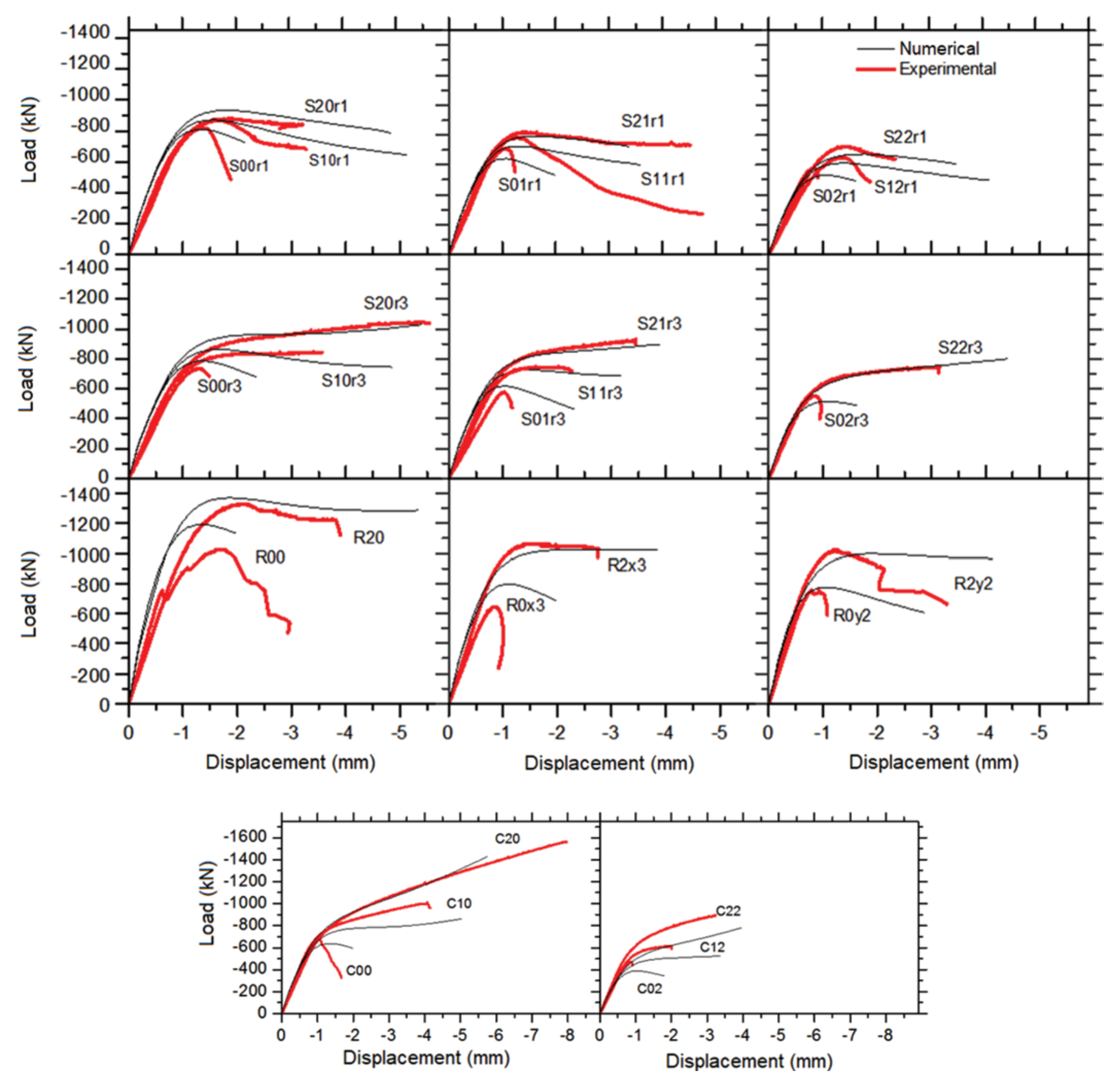

Figure 6

Comparison between the load displacement curves from Carrazedo [17] and the curves from numerical modeling for columns of series 1 to 4 


\section{Results and analysis}

Figures 6 and 7 show the load displacement curves of the modeled columns compared to those obtained by Carrazedo [17]. From that it is possible to highlight a good correlation between the experimental and numerical curves. The numerical model was able to identify the curve tendencies in a very similar way, identifying the gains in load and displacement, and representing the second ascending or descending branch of each situation. Table 5 shows the values of load and displacement at peak $\left(\mathrm{F}_{\mathrm{cc}}\right.$ and $\delta_{\mathrm{cc}}$, respectively) and ultimate $\left(F_{u}\right.$ and $\delta_{u}$, respectively). The average ratios between experimental and numerical values were 1.03 for load and 1.09 for displacement at peak situation. At ultimate condition these ratios were 1.05 for ultimate load and 1.28 ultimate displacements. In addition, the deviations around the average for each of these comparisons are also shown in Table 5, indicating a good approximation of the numerical values with the experimental ones.

Figures 8 and 9 show the FRP strains obtained from numerical modeling along the perimeter at the intermediate columns cross sections compared with the respective strains measured by Carrazedo [17], in the rupture situation. It is possible to observe a good correlation of the numerical model to represent the transverse expansion of the concrete and that the calibration of the dilation angle in the passive confinement was satisfactory. In addition, in the case of eccentric loading, the FRP deformations were larger in the perimeter near the more compressed region of the section.

Figure 10 shows the compressive stresses in the intermediate cross sections of some columns with concentric load. From that it is possible to verify that for columns with square cross sections the stress configuration for the effective confined concrete indicated in Fib [24] or in $\mathrm{ACl} 440.2 \mathrm{R}-08$ [1] can be considered, because this suitably fits the found configuration. However, for the rectangular cross section, it is clear the overlapping of the parabolas delimiting the confined concrete region, which points for the configuration proposed by Tan et al. [15] as the most appropriate.

From the comparison between $1.5 \mathrm{~cm}$ and $3 \mathrm{~cm}$ for rounded corners radius of square cross sections, one can observe that for larger ra- dius columns, higher values of compression stress were obtained and, consequently, greater increase of strength (see Table 5). In regions next to the flat sides of the cross section practically there was no strength increase, different from what occurred next to the rounded corners. In addition, because the membrane effect just occurs in the rounded corners, it was clearly observed that in columns with higher radius the confinement effectiveness was better.

For columns with circular cross sections and concentric load, a perfect distribution of compression stresses was observed. This demonstrates that the uniform confinement and the membrane effect develops efficiently across the entire perimeter of the cross section.

From the compression stresses distribution obtained in different cross sections, the relationship between cross section shape and confinement efficiency with FRP is clear. For circular sections the area of the section is the same as the concrete area effectively confined. For square section the area of confined concrete delimited by the parabolas is smaller in relation to the total area of the section. This ratio is still smaller for rectangular sections, where parabolas cross each other. This allows affirming that for rectangular cross sections with high aspect ratio the parabolas will overlap each other, which will therefore reduce the effective confined area. In Figure 11 the compression stress distribution of circular columns with concentric and eccentric load is shown along a specific path through the cross section. From this, one can see that the region with higher values of compression stress moved in the direction of the eccentricity and even exceeded the compression values at the most compressed edge. However, this region has a smaller width than the rest of the section, which makes the integral of the stresses result in a smaller strength increase for circular columns in the eccentricity situation (see Table 5). In addition, it is also observed that the effectively confined region is delimited by a curved aspect. Because of this, it is not possible to draw a line which is parallel to the neutral line having constant values of compression stresses.

In Figures 12 to 14 one can observe in square and rectangular cross sections that the effectively confined concrete region also moves towards the eccentricity and modifies its distribution aspect. From the center of the cross section to the most compressed edge, the graphs

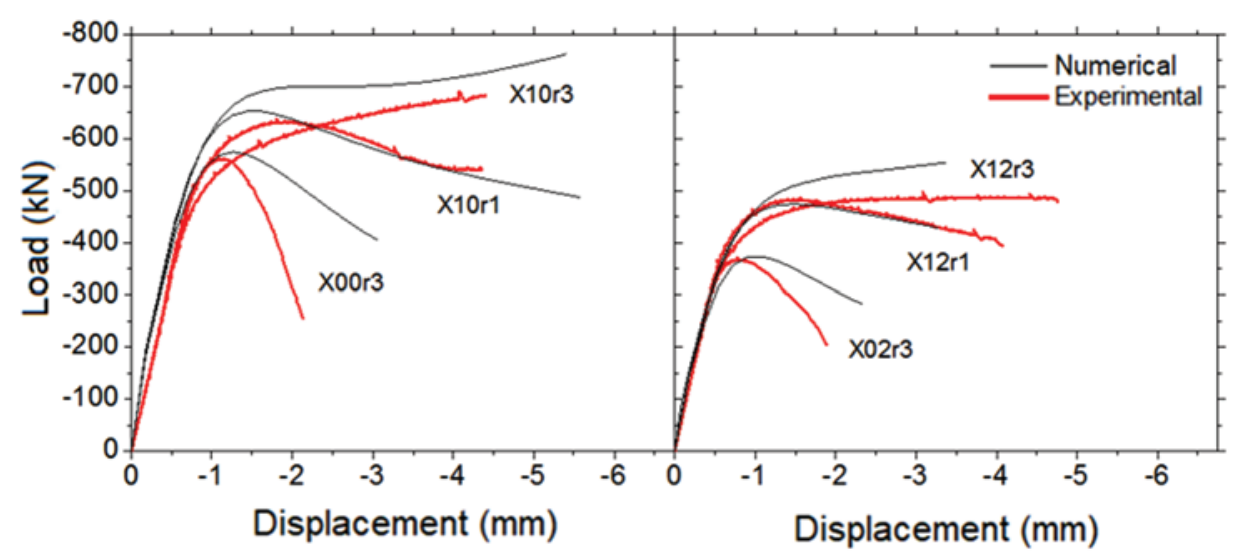

Figure 7

Comparison between the load displacement curves from Carrazedo [17] and the curves from numerical modeling for columns of series 5 
indicate that the compression stresses for the eccentric load situation were generally higher in relation to concentric load situation. As the width of the section remains the same, a greater region is proportionately confined in comparison to the circular shape. This justifies the fact that the strength gain for square section is practically the same or slightly higher in cases of eccentricity than the concentric load (see Table 5). This allows affirming that the eccentricity is not harmful when square and rectangular sections are strengthened FRP.

From graphs shown in Figures 15 and 16 it is possible to demonstrate that the increase in eccentricity has little influence on efficiency of strengthening in square and rectangular sections here repre- sented by the gain ratio of stress $\mathrm{f}_{\mathrm{cc}} / \mathrm{f}_{\mathrm{c}}$ and the strain ratio of strain $\varepsilon_{\mathrm{cc}}$ $/ \varepsilon_{\mathrm{c}}$. These gains remain practically the same and in some cases they increase slightly as the eccentricity increases. On the other hand, for the circular sections, it is clear that the increase in eccentricity provides less gain in strength and strain due to FRP confinement.

\section{Conclusion}

The numerical model used was able to represent the passive confinement mechanism of the concrete columns with square, rectangular and circular cross sections, which have regions of high

\section{Table 5}

Comparison of load and displacement between the values measured by Carrazedo [17] and the ones obtained by the numerical modeling

\begin{tabular}{|c|c|c|c|c|c|c|c|c|c|c|c|c|c|}
\hline Column & $\begin{array}{l}F_{\text {ccexp }} \\
(\mathrm{kN})\end{array}$ & $\begin{array}{l}F_{c c, e x p} \\
F_{c 0, e x p}\end{array}$ & $\begin{array}{l}F_{\text {cc,num }} \\
(\mathrm{KN})\end{array}$ & $\begin{array}{l}F_{c c, n u m} \\
F_{c c, e x p}\end{array}$ & $\begin{array}{l}\delta_{c c, e x p} \\
(\mathrm{~mm})\end{array}$ & $\begin{array}{l}\delta_{\text {cc,num }} \\
(\mathrm{mm}) \\
\end{array}$ & $\frac{\delta_{c c, n u m}}{\delta_{c c, \mathrm{xpp}}}$ & $\begin{array}{l}F_{\text {uexp }} \\
(\mathrm{kN})\end{array}$ & $\begin{array}{l}\mathrm{F}_{\text {unum }} \\
\text { (kN) }\end{array}$ & $\frac{F_{u, n u m}}{F_{u, e x p}}$ & $\begin{array}{l}\delta_{\mathrm{uexp}} \\
(\mathrm{mm})\end{array}$ & $\begin{array}{l}\delta_{\mathrm{u}, \mathrm{num}} \\
(\mathrm{mm})\end{array}$ & $\begin{array}{l}\frac{\delta_{\text {u,num }}}{\delta_{\text {u,exp }}} \\
\end{array}$ \\
\hline SOOr1 & 815 & - & 808 & 0.99 & 1.15 & 1.26 & 0.91 & - & - & - & - & - & - \\
\hline S10r1 & 872 & 1.07 & 872 & 1.00 & 1.34 & 1.58 & 0.92 & 678 & 645 & 0.95 & 3.32 & 5.22 & 1.57 \\
\hline S20r1 & 883 & 1.08 & 932 & 1.06 & 1.76 & 1.8 & 0.92 & 842 & 785 & 0.93 & 3.25 & 4.92 & 1.51 \\
\hline S01r1 & 709 & - & 652 & 0.92 & 0.76 & 1.26 & 1.19 & - & - & - & - & - & - \\
\hline S11r1 & 785 & 1.11 & 784 & 1.00 & 1.13 & 1.26 & 1.04 & 272 & 601 & 2.21 & 4.76 & 3.6 & 0.76 \\
\hline S21r1 & 816 & 1.15 & 821 & 1.01 & 1.3 & 1.62 & 1.13 & 733 & 722 & 0.98 & 4.53 & 3.39 & 0.75 \\
\hline SO2r1 & 578 & - & 575 & 0.99 & 0.68 & 1.08 & 1.30 & - & - & - & - & - & - \\
\hline $\mathrm{S} 12 \mathrm{r} 1$ & 650 & 1.13 & 653 & 1.00 & 1.06 & 1.44 & 1.04 & 488 & 497 & 1.02 & 1.9 & 4.14 & 2.18 \\
\hline S22r1 & 722 & 1.25 & 724 & 1.00 & 1.23 & 1.80 & 1.24 & 641 & 605 & 0.94 & 2.37 & 3.5 & 1.48 \\
\hline soOr3 & 730 & - & 784 & 1.07 & 1.01 & 1.44 & 1.12 & - & - & - & - & - & - \\
\hline s10r3 & 846 & 1.16 & 864 & 1.02 & 3.27 & 1.62 & 0.48 & 840 & 746 & 0.89 & 3.56 & 4.86 & 1.37 \\
\hline $\mathrm{SO} 2 \mathrm{r} 3$ & 1049 & 1.44 & 1028 & 0.98 & 5.23 & 5.4 & 0.99 & 1047 & 1028 & 0.98 & 5.44 & 5.40 & 0.99 \\
\hline s01r3 & 573 & - & 632 & 1.10 & 1.03 & 1.08 & 1.05 & - & - & - & - & - & - \\
\hline S11r3 & 716 & 1.25 & 727 & 1.02 & 1.81 & 1.44 & 0.62 & 722 & 684 & 0.95 & 2.1 & 3.24 & 1.54 \\
\hline S11r3 & 742 & 1.29 & 749 & 1.01 & 1.94 & 1.44 & 0.67 & 742 & 684 & 0.92 & 2.15 & 3.24 & 1.51 \\
\hline $\mathrm{S} 21 \mathrm{r} 3$ & 929 & 1.62 & 932 & 1.00 & 3.30 & 3.96 & 1.13 & 929 & 898 & 0.97 & 3.5 & 3.96 & 1.13 \\
\hline $\mathrm{SO} 2 \mathrm{r} 3$ & 552 & - & 557 & 1.01 & 0.68 & 1.08 & 1.26 & - & - & - & - & - & - \\
\hline $\mathrm{S} 22 \mathrm{r} 3$ & 745 & 1.35 & 753 & 1.01 & 3.02 & 4.14 & 1.32 & 745 & 764 & 1.03 & 3.14 & 4.14 & 1.32 \\
\hline ROr3 & 1019 & - & 1191 & 1.17 & 1.06 & 1.26 & 0.80 & - & - & - & - & - & - \\
\hline R2r3 & 1331 & 1.31 & 1370 & 1.03 & 1.69 & 1.85 & 0.88 & 1120 & 1285 & 1.15 & 3.90 & 5.34 & 1.37 \\
\hline ROx3 & 646 & - & 846 & 1.31 & 0.68 & 1.08 & 1.32 & - & - & - & - & - & - \\
\hline $\mathrm{R} 2 \times 3$ & 972 & 1.50 & 1063 & 1.09 & 1.42 & 3.85 & 1.4 & 1060 & 1023 & 0.96 & 1.54 & 3.85 & 2.50 \\
\hline ROy2 & 756 & - & 846 & 1.12 & 0.68 & 1.08 & 1.37 & - & - & - & - & - & - \\
\hline R2y2 & 1020 & 1.35 & 1019 & 1.00 & 1.42 & 1.98 & 1.62 & 661 & 997 & 1.51 & 3.27 & 1.98 & 0.61 \\
\hline $\mathrm{COO}$ & 682 & - & 636 & 0.93 & 1.02 & 1.26 & 1.21 & - & - & - & - & - & - \\
\hline $\mathrm{C} 10$ & 1013 & 1.49 & 863 & 0.85 & 4.14 & 5.04 & 1.24 & 1000 & 863 & 0.86 & 4.08 & 5.04 & 1.24 \\
\hline C20 & 1562 & 2.29 & 1431 & 0.92 & 8.00 & 5.76 & 0.72 & 1560 & 1431 & 0.92 & 8.00 & 5.76 & 0.72 \\
\hline $\mathrm{CO} 2$ & 469 & - & 470 & 1.00 & 0.72 & 1.08 & 1.26 & - & - & - & - & - & - \\
\hline $\mathrm{C} 12$ & 611 & 1.30 & 612 & 1.00 & 1.77 & 3.35 & 1.66 & 612 & 523 & 0.86 & 2.02 & 3.35 & 1.66 \\
\hline $\mathrm{C} 22$ & 892 & 1.90 & 914 & 1.02 & 2.90 & 3.96 & 1.13 & 892 & 780 & 0.87 & 3.52 & 3.96 & 1.13 \\
\hline X00 & 562 & - & 574 & 1.02 & 1.21 & 1.26 & 1.18 & - & - & - & - & - & - \\
\hline X10r1 & 638 & 1.14 & 652 & 1.02 & 1.73 & 1.44 & 0.76 & 540 & 486 & 0.90 & 4.35 & 5.58 & 1.28 \\
\hline x10r3 & 690 & 1.23 & 762 & 1.10 & 3.77 & 5.4 & 1.33 & 690 & 762 & 1.10 & 4.39 & 5.4 & 1.23 \\
\hline$x 02 r 3$ & 367 & - & 470 & 1.28 & 0.72 & 1.08 & 1.35 & - & - & - & - & - & - \\
\hline $\mathrm{X} 12 \mathrm{r} 1$ & 483 & 1.32 & 485 & 1.00 & 1.09 & 1.47 & 0.99 & 394 & 428 & 1.09 & 4.07 & 3.27 & 0.8 \\
\hline $\mathrm{X} 12 \mathrm{r} 3$ & 487 & 1.33 & 498 & 1.02 & 1.88 & 3.37 & 0.73 & 487 & 552 & 1.13 & 4.59 & 3.37 & 0.73 \\
\hline \multicolumn{4}{|c|}{ Average: } & 1.03 & & & 1.03 & & & 1.05 & & & 1.28 \\
\hline \multicolumn{4}{|c|}{ Deviation from the average: } & 0.06 & & & 0.06 & & & 0.17 & & & 0.34 \\
\hline
\end{tabular}



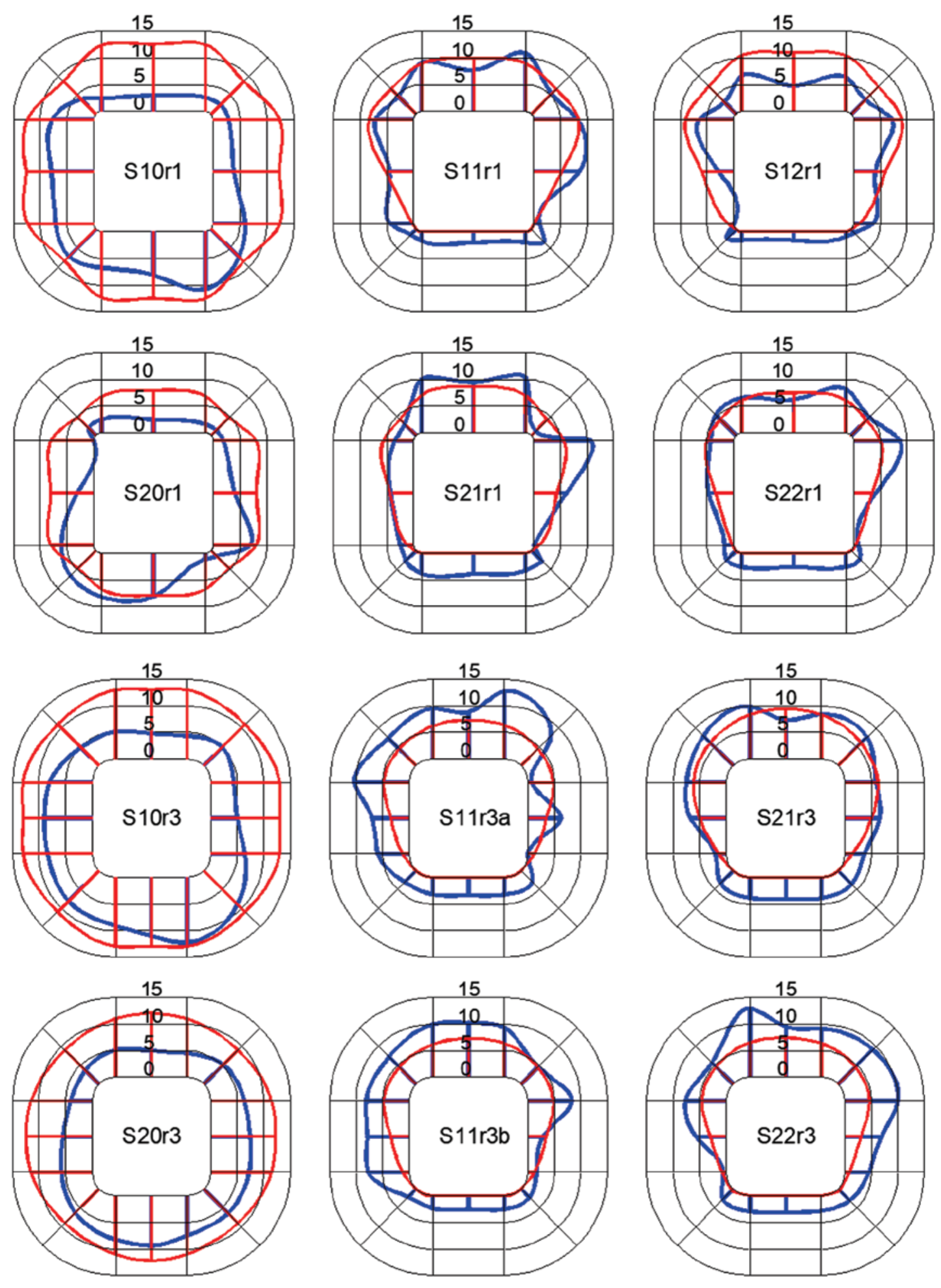

Experimental Numerical modeling

\section{Figure 8}

FRP strains in the perimeter of columns midsections: comparison between numerical and experimental values by Carrazedo [17]. Series 1 and 2 (unit in \%o) 
and low confinement. There was a good correlation when comparing the experimental and numerical load displacement curves. It was possible to adequately represent the dilatation of the concrete, which was calibrated with experimental values of FRP tensile strains at the cross sections perimeters.

It was possible to observe the compression stresses distribution in different cross sections. In square sections the effectively confined region forms near the rounded corners and it is delimited by parabolas starting at $45^{\circ}$ near the rounded corners. For rectangular sections, because of the larger sides of the section, the parabolas touch each other. This divide the confined region into two regions located closer to the smallest sides of the cross section.

For eccentric load, the most compressed region moves in the direction of eccentricity and the stress reaches higher values than in the concentric situation. However, this was not harmful for square and rectangular sections, because the width of the section remains the same and the stress values exceed the values observed in the concentric situation for a larger portion of the cross section. In some cases the strength gain was slightly higher in eccentricity situation. For the circular sections, the presence of eccentricity was detrimental because the width of the section decreases as it
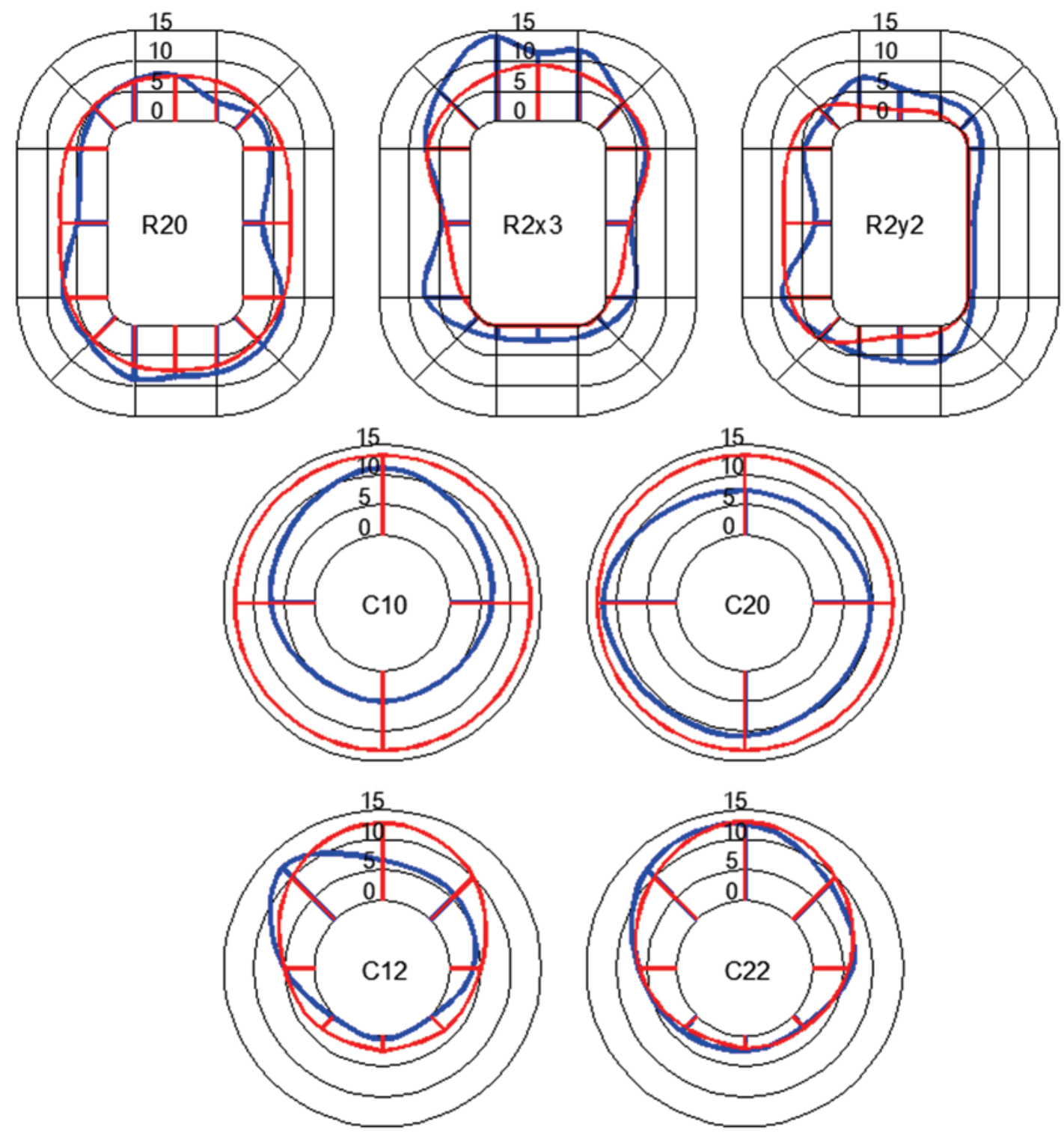

\section{Experimental}

\section{Numerical modeling}

\section{Figure 9}

FRP strains in the perimeter of columns midsections: comparison between numerical and experimental values by Carrazedo [17]. Series 3 and 4 (unit in \%o) 


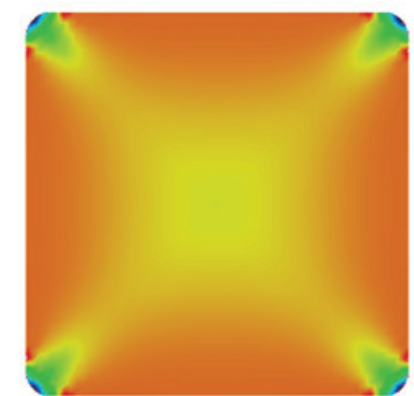

S20r1

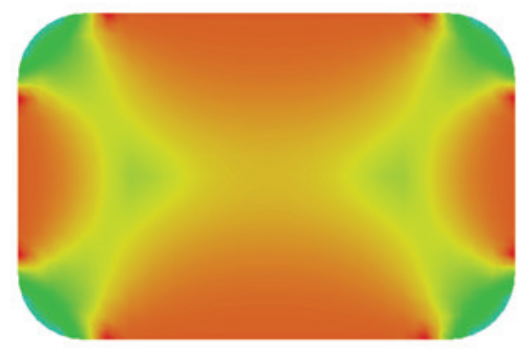

R20
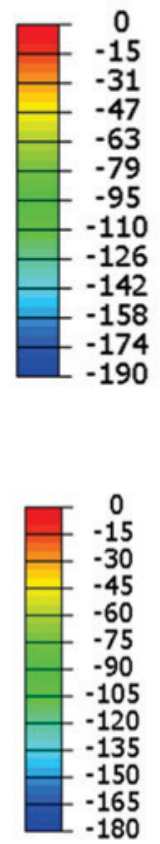

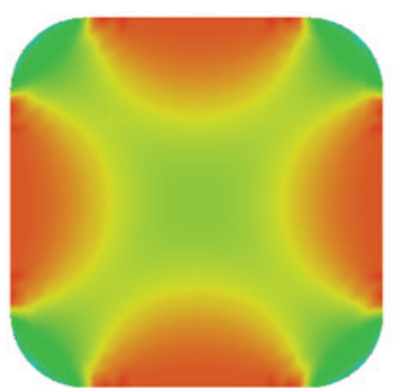

S20r3

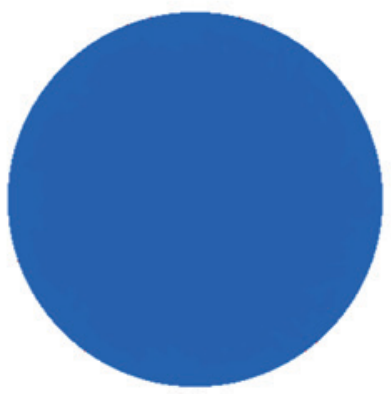

C20
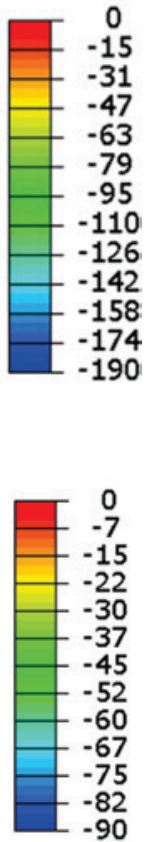

\section{Figure 10}

Axial compression stress distribution in columns confined with FRP obtained by numerical modeling (unit in MPa)

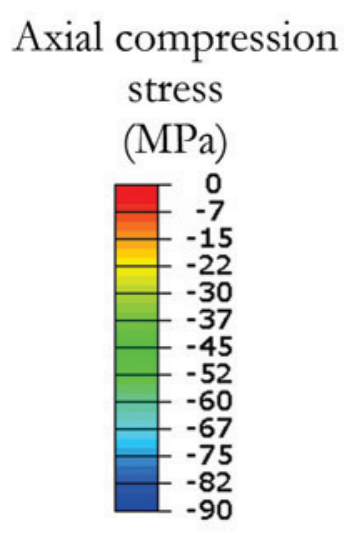

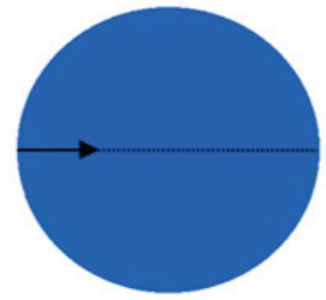

C20

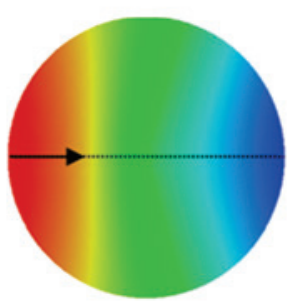

$\mathrm{C} 22$

(a)

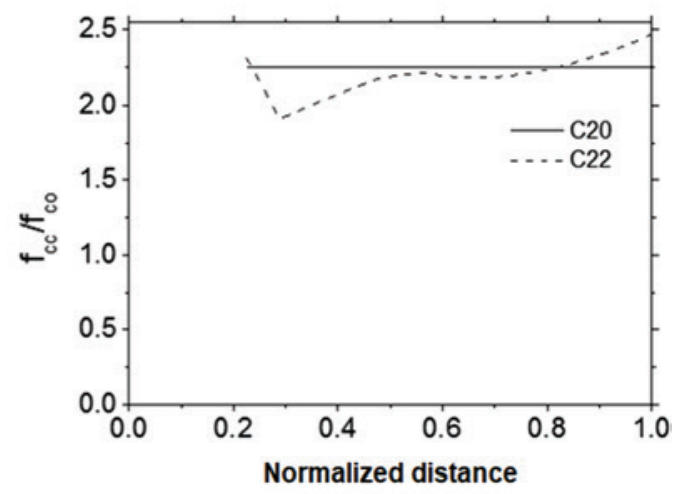

(b)

Figure 11

Axial compression stress in circular columns C20 and C22 (unit in MPa): (a) stress distribution; (b) stress gain throughout the indicated paths (a) 


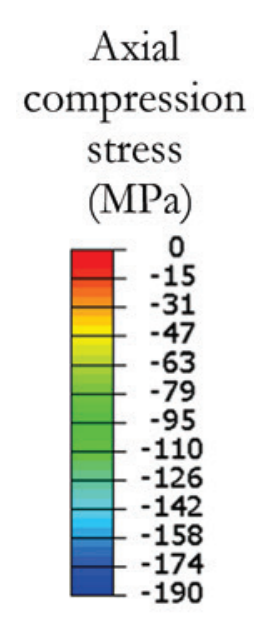

(a)
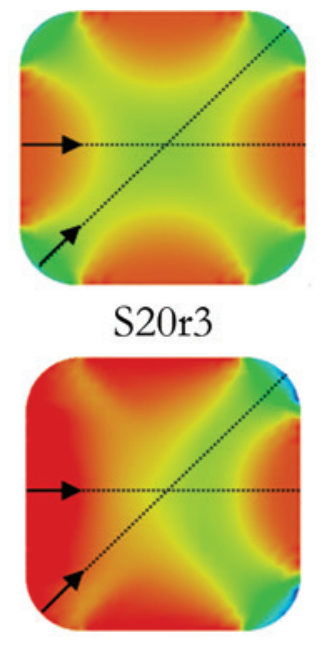

$\mathrm{S} 20 \mathrm{r} 3$

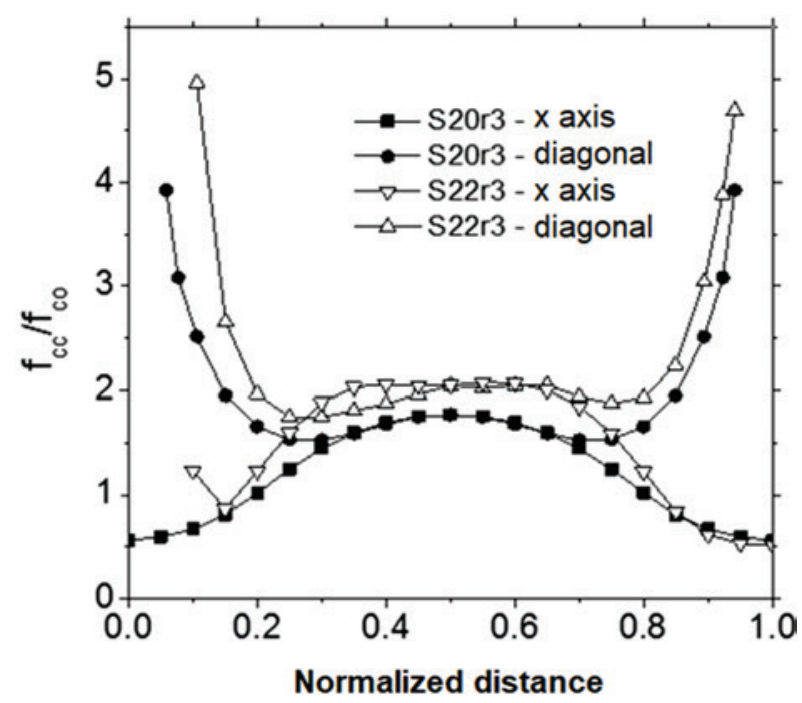

(b)

\section{Figure 12}

Axial compression stress in circular columns S2Or3 and S2Or3 (unit in MPa): (a) stress distribution; (b) stress gain throughout the indicated paths (a)
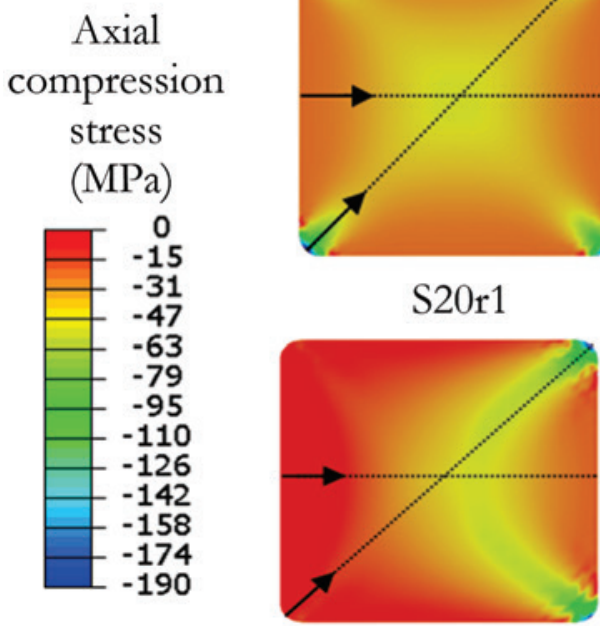

$\mathrm{S} 22 \mathrm{r} 1$

(a)

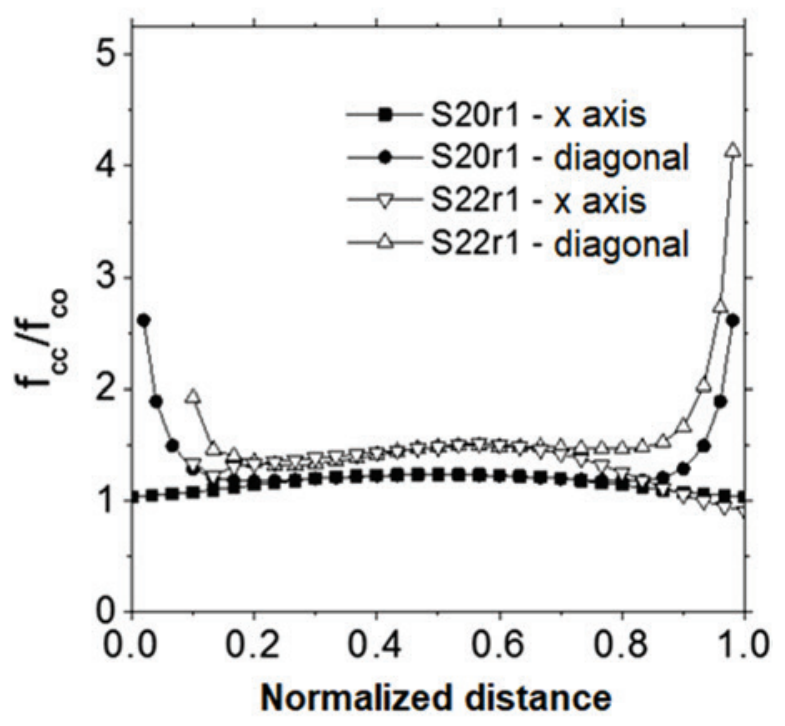

(b)

Figure 13

Axial compression stress in circular columns S2Or1 and S22r1 (unit in MPa): (a) stress distribution; (b) stress gain throughout the indicated paths (a) 


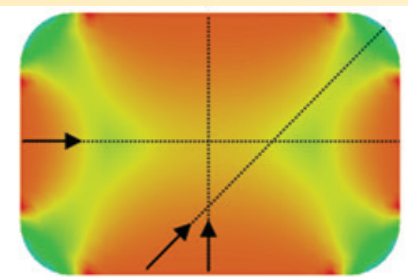

R20
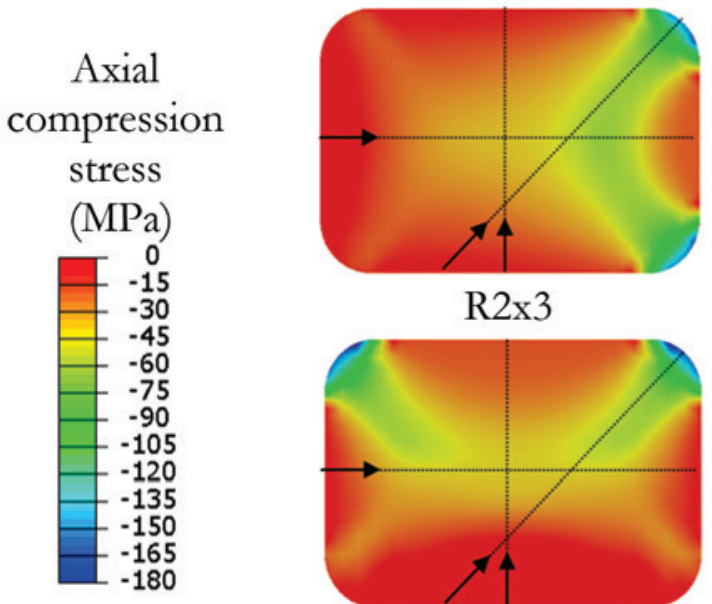

$\mathrm{R} 2 \mathrm{x} 3$

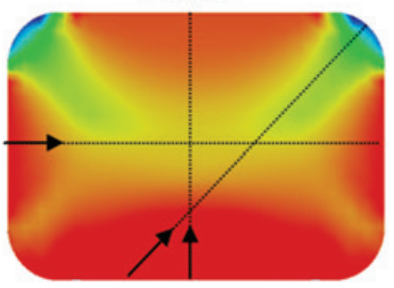

$\mathrm{R} 2 \mathrm{y} 2$

(a)
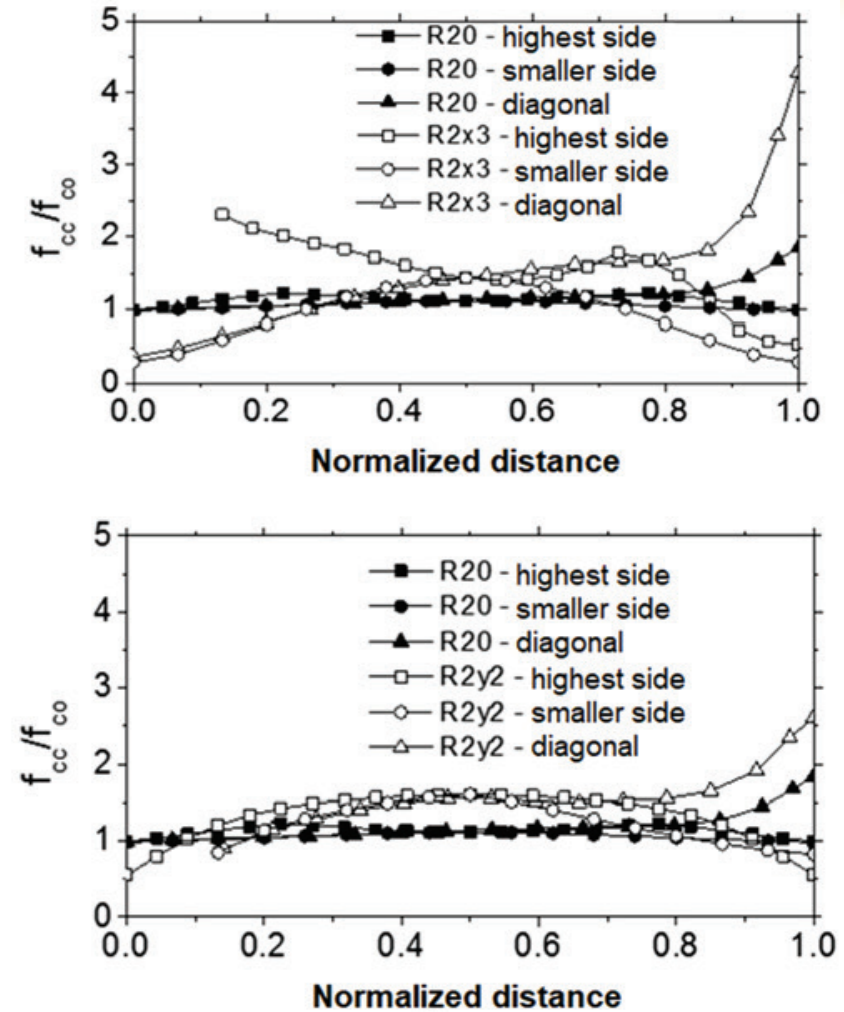

(b)

\section{Figure 14}

Axial compression stress in circular columns R2x3 and R2y2 (unit in MPa): (a) stress distribution; (b) stress gain throughout the indicated paths (a)
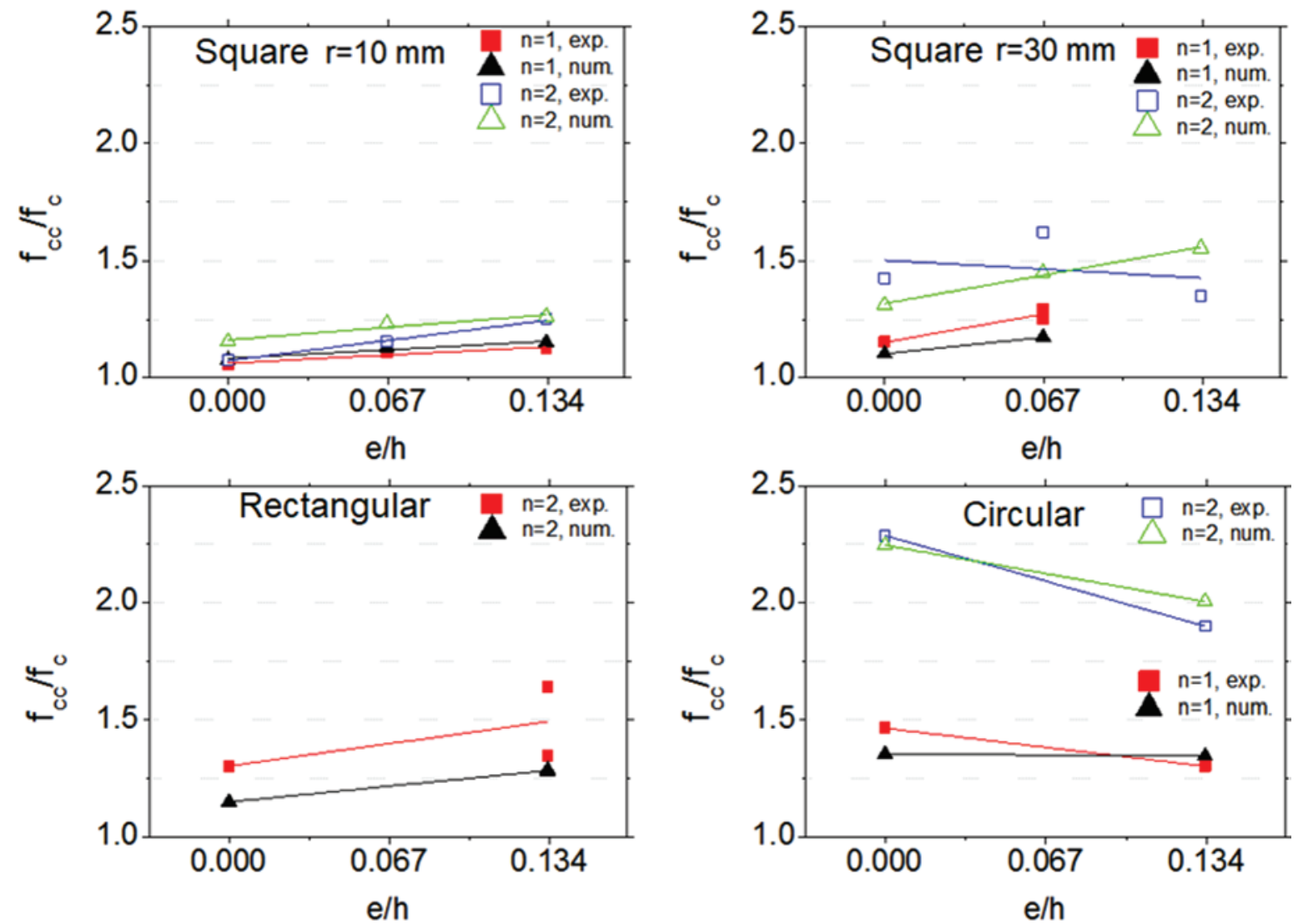

Figure 15

Influence of relative eccentricity in the stress gain in the columns of series 1 to 4 

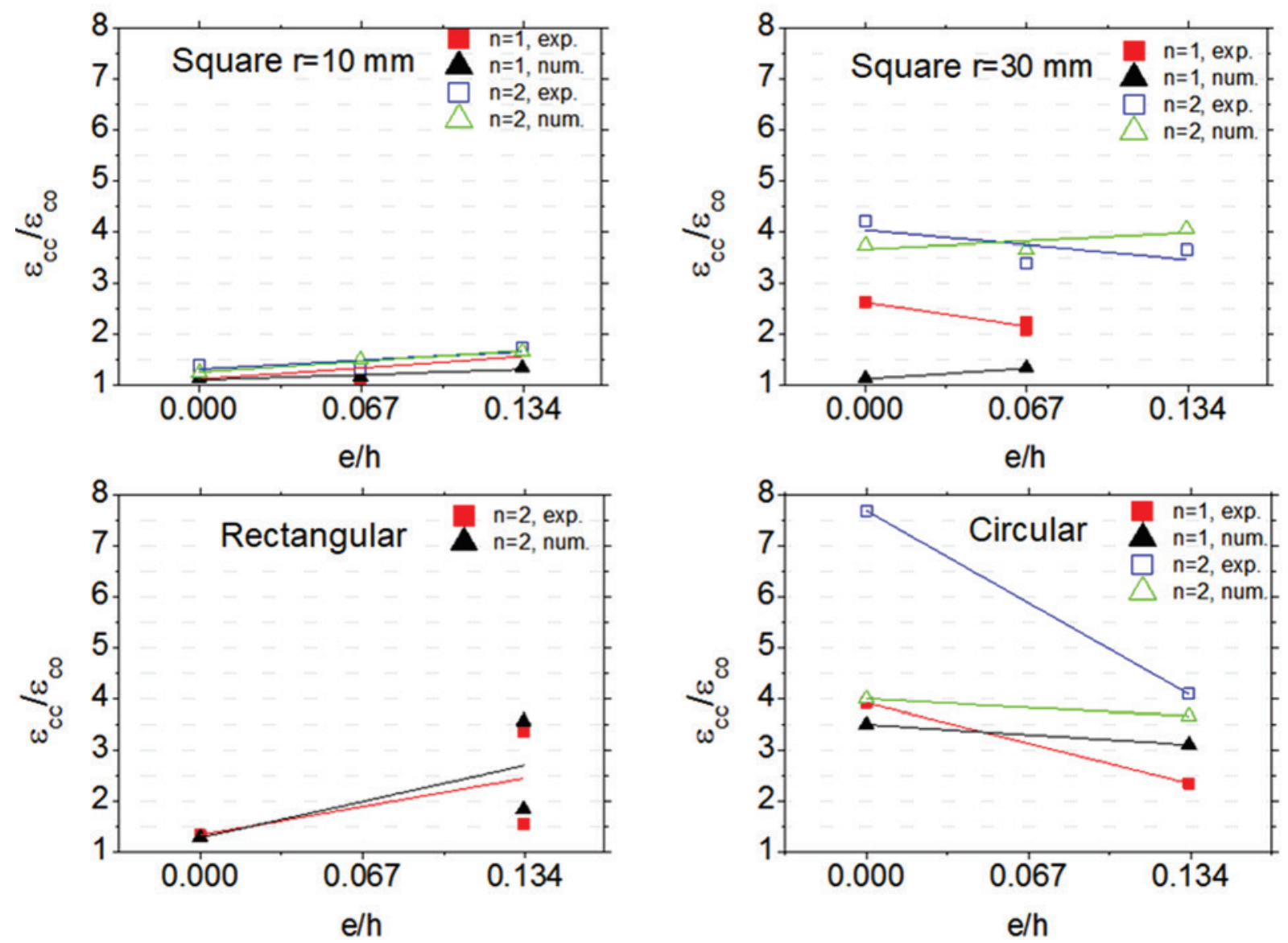

Figure 16

Influence of relative eccentricity in the strain gain in the columns of series 1 to 4

approaches the more compressed edge. This justifies the fact that for circular sections the strength gain was lower.

\section{Acknowledgement}

The authors thank the Departamento de Estruturas of Escola de Engenharia de São Carlos - Universidade de São Paulo for the financial resources necessary to development of this research.

\section{References}

[1] American Concrete Intitute, "Guide for the Design and Construction of Externally Bonded FRP Systems." ACl 440 Detroit, Mich, 2008.

[2] F. E. Richart, A. Brandtzaeg, and R. L. Brown, "A study of the failure of concrete under combined compressive stresses.," Eng. Exp. Stn. Bull. No. 185, Univ. Illinois, Urbana, III., 1928.

[3] L. Lam and J. G. Teng, "Design-oriented Stress-Strain Model for FRP-confined Concrete in Rectangular Columns," J. Reinf. Plast. Compos., vol. 22, pp. 1149-1187, 2003.

[4] I. a. E. M. Shehata, "Strength of short concrete columns confined with CFRP sheets," Mater. Struct., vol. 35, no. 245 , pp. 50-58, 2001.

[5] M. El Sayed and T. El Maaddawy, "Analytical model for prediction of load capacity of RC columns confined with CFRP under uniaxial and biaxial eccentric loading," Mater. Struct., vol. 44, no. 1, pp. 299-311, Jun. 2010.

[6] N. Nisticò, "R.C. square sections confined by FRP: A numerical procedure for predicting stress-strain relationships," Compos. Part B Eng., vol. 59, pp. 238-247, Mar. 2014.

[7] P. Rochette and P. Labossière, "Axial testing of rectangular column models confined with composites," J. Compos. Constr., vol. 6, no. May 2011, pp. 129-136, 2000.

[8] X. Yang, "Effect of Corner Radius on the Performance of Externally Bonded FRP Reinforcement," pp. 197-204, 2001.

[9] R. Carrazedo and J. B. De Hanai, "Concrete Prisms and Cylinders Wrapped by FRP Loaded in Compression with Small Eccentricities," J. Compos. Constr., vol. 21, no. 4, pp. 1-14, 2016.

[10] M. N. Youssef, M. Q. Feng, and A. S. Mosallam, "Stress-strain model for concrete confined by FRP composites," Compos. Part B Eng., vol. 38, no. 5-6, pp. 614-628, Jul. 2007.

[11] A. Ilki, O. Peker, E. Karamuk, C. Demir, and N. Kumbasar, "FRP Retrofit of Low and Medium Strength Circular and 
Rectangular Reinforced Concrete Columns," J. Mater. Civ. Eng., vol. 20, no. 2, p. 169, 2008.

[12] H. Toutanji, M. Han, J. Gilbert, and S. Matthys, "Behavior of Large-Scale Rectangular Columns Confined with FRP Composites," no. FEBRUARY, pp. 62-71, 2010.

[13] M. Maalej, S. Tanwongsval, and P. Paramasivam, "Modelling of rectangular RC columns strengthened with FRP," Cem. Concr. Compos., vol. 25, no. 2, pp. 263-276, 2003.

[14] F. Micelli and R. Modarelli, "Experimental and analytical study on properties affecting the behaviour of FRPconfined concrete," Compos. Part B Eng., vol. 45, no. 1, pp. 1420-1431, Feb. 2013.

[15] K. H. Tan, T. Bhowmik, and T. Balendra, "Confinement model for FRP-bonded capsule-shaped concrete columns," Eng. Struct., vol. 51, pp. 51-59, Jun. 2013.

[16] A. de P. Machado, Reforço de estruturas de concreto armado com fibras de carbono, 1st ed. São Paulo - SP., 2002.

[17] R. Carrazedo, "Mecanismos de confinamento em pilares de concreto encamisados com polímeros reforçados com fibras submetidos à flexo- compressão.," Tese (Doutorado). Esc. Eng. São Carlos, Univ. São Paulo.Escola Eng. São Carlos, Univ. São Paulo, p. 242, 2005.

[18] O. Chaallal, M. Shahawy, and M. Hassan, "Performance of Axially Loaded Short Rectangular Columns Strengthened with Carbon Fiber-Reinforced Polymer Wrapping," J. Compos. Constr., vol. 7, no. 3, p. 200, 2003.

[19] M. Harajli, "Axial stress-strain relationship for FRP confined circular and rectangular concrete columns," Cem. Concr. Compos., vol. 28, no. 10, pp. 938-948, Nov. 2006.

[20] R. Kumutha, R. Vaidyanathan, and M. S. Palanichamy, "Behaviour of reinforced concrete rectangular columns strengthened using GFRP," Cem. Concr. Compos., vol. 29, no. 8, pp. 609-615, Sep. 2007.

[21] Y.-F. Wu and Y.-Y. Wei, "Effect of cross sectional aspect ratio on the strength of CFRP-confined rectangular concrete columns," Eng. Struct., vol. 32, no. 1, pp. 32-45, Jan. 2010.

[22] Z. Yan and C. P. Pantelides, "Concrete column shape modification with FRP shells and expansive cement concrete," Constr. Build. Mater., vol. 25, no. 1, pp. 396-405, Jan. 2010.

[23] T. Ozbakkaloglu, "Concrete-Filled FRP Tubes : Manufacture and Testing of New Forms Designed for Improved Performance," J. Compos. Constr., no. April, pp. 280-291, 2013.

[24] Fédération Internationale du Béton, "Externally bonded FRP reinforcement for RC structures." Bulletin No. 14, Technical Rep., Lausanne, Switzerland., 2001.

[25] S. Rocca, N. Galati, and A. Nanni, "Review of Design Guidelines for FRP Confinement of Reinforced Concrete Columns of Noncircular Cross Sections," vol. 12, no. 1, pp. 80-92, 2008.

[26] "ABAQUS - Theory Manual." DASSAULT SYSTÉMES, Providence USA, 2012.

[27] J. Lubliner, J. Oliver, S. OLLer, and E. Õnate, "A PLASTICDAMAGE MODEL FOR CONCRETE," Int. J. Solids Struct., vol. 25, no. 3, pp. 299-326, 1989.

[28] J. H. Lee and G. L. Fenves, "Plastic-damage model for cyclic loading of concrete structures," J. Eng. Mech., vol. 124, no. 8, pp. 892-900, 1998.

[29] T. Ozbakkaloglu, A. Gholampour, and J. C. Lim, "Damage-
Plasticity Model for FRP-Confined Normal-Strength and HighStrength Concrete," J. Compos. Constr., pp. 1-13, 2016.

[30] T. H. Wee, M. S. Chin, and M. A. Mansur, "Stress-Strain Relationship of High-Strength Fiber Concrete in Compression," J. Mater. Civ. Eng., vol. 11, no. 1, pp. 21-29, 1996.

[31] CEB-FIP, "COMITE EURO-INTERNACIONAL DU BÉTON. CEB-FIP: Model code 1990. Bulletin D'Information, Paris, n. 203-205." 1993. 